\title{
QUEEN'S
UNIVERSITY
BELFAST
}

\section{Promoting readiness to practice: which learning activities promote competence and professional identity for student social workers during practice learning?}

Roulston, A., Cleak, H., \& Vreugdenhil, A. (2018). Promoting readiness to practice: which learning activities promote competence and professional identity for student social workers during practice learning? Journal of Social Work Education. https://doi.org/10.1080/10437797.2017.1336140

Published in:

Journal of Social Work Education

Document Version:

Peer reviewed version

Queen's University Belfast - Research Portal:

Link to publication record in Queen's University Belfast Research Portal

\section{Publisher rights}

(c) 2018 Council on Social Work Education.

This is an Accepted Manuscript of an article published by Taylor \& Francis in Journal of Social Work Education on [date of publication] available online: http://www.tandfonline.com/[Article DOI].

\section{General rights}

Copyright for the publications made accessible via the Queen's University Belfast Research Portal is retained by the author(s) and / or other copyright owners and it is a condition of accessing these publications that users recognise and abide by the legal requirements associated with these rights.

Take down policy

The Research Portal is Queen's institutional repository that provides access to Queen's research output. Every effort has been made to ensure that content in the Research Portal does not infringe any person's rights, or applicable UK laws. If you discover content in the Research Portal that you believe breaches copyright or violates any law, please contact openaccess@qub.ac.uk. 
Promoting readiness to practice: Which learning activities promote competence and professional identity for student social workers during practice learning?

\section{Introduction}

Practice learning is integral to the curriculum for all qualifying students attending accredited Schools of Social Work. However, the ability of academic institutions to produce 'ethical, competent, innovative, effective clinical social workers' is conditional on students receiving quality practice placements (Bogo, 2015, p. 317). In contrast to a number of other disciplines (Bogo, 2015), academic institutions are dependent upon social work agencies to resource student learning through offering: opportunities to integrate classroom learning into practice (Power \& Bogo, 2002); high quality opportunities for direct work with service users and carers (Department of Health, Social Services and Public Safety Northern Ireland (DHSSPSNI, 2010); regular and sufficient supervision of work performance (College of Social Work, 2012) and practice teachers to guide developing knowledge, skills and critical thinking in readiness for practice (Furness \& Gilligan, 2004).

\section{The changing context of practice placements}

Globally, social work students are offered field or practice placements through established working relationships between academic institutions and health and social care organisations. These placements are traditionally delivered by matching each student to an agency or team and assigning them a practice educator/ teacher who then assists the student to integrate and apply knowledge, skills, values to practice (Bogo, 2015). However, economic and social transformations over the last two decades present new challenges for health and social care, which have resulted in the expansion of field education, competition to secure placements, stressful working environments in agency settings and the inconsistent management of 
placements (McKee, Muskat \& Perlman, 2015). Due to changing service user and carer needs, efforts to professionalise the workforce in public social services have prompted the need for a flexible and skilled workforce (Bogo, Regehr, Woodford, Hughes, Power, \& Regehr, 2006; Wilson, Walsh \& Kirby, 2008). Croisdale-Appleby (2014) proposed considering social workers as professionally competent and confident practitioners, reflecting the global definition of promoting practice (International Federation of Social Workers, 2014). He indicated that as the health and social care landscape is being transformed, innovative strategies to equip the workforce as social work practitioners, professionals and social scientists are required. The Social Work Review Board established changes to social work education and practice learning across the United Kingdom (Social Work Task Force, 2009), which standardised training for greater transparency and professional accountability, and implemented accreditation standards which require students to be exposed to specific learning activities during placement (Northern Ireland Degree in Social Work Partnership, 2015). However, the contribution of standardised learning activities to practice competence and professional identity is only beginning to emerge through research (Author, 2015; 2016).

In Northern Ireland, the standardisation of professional social work training led to: increased student enrolments, tighter regulation and inspection of the profession as a whole (Skehill, 2005); an increase in practice learning to 200 days (Lefevre, 2005); the registration of practice learning providers and social workers with the Northern Ireland Social Care Council (NISCC); and the formal accreditation and training of practice teachers at Master's level. Despite research indicating that $75 \%$ of newly graduated social workers believed their degree and placement had provided sufficient knowledge and skills to prepare them for their current post (Bates, Immins, Parker, Keen, Rutter, Brown \& Zsigo. 2010), others expressed concern that social work education does not adequately prepare social workers for practice 
(Department of Health, 2002; Williams, 2009; Donnellan \& Jack, 2009; Houston \& McColgan, 2014). Bellinger (2010, p. 609) argues that the new standards, regulations and requirements have 'eroded the previous expectation of quality’ which had previously been suggested by others who indicated that increasing student enrolments led to a shortage of placements (Nixon \& Murr, 2006; Williams, 2009), with some organisations placing students in agency settings with no social work presence (Furness \& Gilligan, 2004). Likewise, pressure to meet increased quotas may have placed practice teachers under more pressure and compromised gate-keeping entry into the profession (Sowbell, 2012). Similar trends can be seen in Australia, Canada and the United States with a growing number of universities offering social work programs which increased pressure on agencies to meet demand (Regehr, 2013; Bogo, 2006). Given the variable nature of practice learning settings and individual approaches adopted by practice teachers, assessing student competence is complex and needs to be regulated and standardised.

\section{Learning activities on placement}

Practice learning enables students to begin identifying themselves as social workers and internalising the role (Nixon \& Murr, 2006) and it promotes the socialisation of students 'to think and act like a social worker' (Bogo, 2015, p. 318). These are generally achieved through students observing a role model practising social work (Lee \& Fortune, 2013); working independently with service users (Fortune \& Kaye, 2002); carrying a caseload independent of their practice teacher (Csiernik, 2001); participating in a variety of tasks (Fortune, Feathers, Rook, Smollen, Stemerman, \& Tucker, 1985); receiving critical feedback about their own practice after being observed (Fortune, McCarthy \& Abramson, 2001; DHSSPSNI, 2010; Bogo, 2015); and self-assessing their practice (Boud, 1995). Other learning activities undertaken during placement may include reviewing recorded interactions, 
written records and verbal reports from direct practice, which underpin learning in student supervision (Bogo, 2010; Fortune \& Lee, 2004).

Despite research indicating that students with more opportunities to observe are more satisfied and perform better (Fortune, McCarthy \& Abramson, 2001), recent research in Australia reported that half of the qualifying social work students did not regularly observe social work practice or have their own practice observed (Author’s own, 2012). It has also been acknowledged that observing role models is not sufficient to enable students to learn how to practice social work (Shardlow \& Doel, 1996) and that 'there are differences between the students' perceptions, skills, and learning activities depending on their developmental process’ (Lee \& Fortune, 2013, p. 422). For example, research showed that in the early stages of professional training students are highly dependent and prefer a structured learning environment. Whereas mature and advanced students are more independent, have increased self-awareness and can provide the context, links to practice principles and critically appraise their work (Lee \& Fortune, 2013, p. 423).

Amidst claims that social work training falls short of producing the flexible and skilled workforce required, changes were introduced across the United Kingdom to promote professional competence and readiness to practice. Despite the standardisation and regulation of practice learning and student supervision across Northern Ireland, assessing competence remains challenging with variable placement settings, service user groups and models of supervision adopted by individual practice teachers or agencies. This exploration of social work students' experiences of supervision and learning during practice placements is timely and will contribute to a growing body of knowledge around which learning activities contribute most to readiness to practice, competence and professional identity. 


\section{Research Aims}

The aims of this research study were:

- To identify learning activities that students found most useful in developing readiness for practice in terms of practice competence and professional social work identity;

- To identify what assisted and what would have improved student learning during placement; and

- To explore differences in the reported usefulness of the learning activities across placement settings and student groups.

This builds on two other aspects of the original study (Author's own, 2016), which explored the frequency of supervision and learning activities students received on placement.

\section{Method}

This study used a cross-sectional survey to explore the experiences and views of social work students from the two Northern Irish universities regarding their learning during practice placement. Ethical approval was obtained from the School Research Ethics Committee at the School of Sociology, Social Policy and Social Work at Queen's University Belfast (REF: EC/074). This approval was accepted by the Research Ethics committee in Ulster University to cover data collection in both settings.

\section{Questionnaire design}

The survey instrument was based on a questionnaire originally developed for the Australian context (Author’s own, 2012; 2015). The terminology was adapted to reflect the Northern Ireland Framework Specification for the Degree in Social Work (DHSSPSNI, 2014) which highlights key roles derived from the 'National Occupational Standards for Social Work' (NISCC, 2011). Each Standard includes performance criteria and core statements for skills, 
knowledge and understanding. The self-administered, written questionnaire collected information about the: Practice Learning Opportunity (PLO) level (first or final); service user group (adult or children’s services); setting (fieldwork, residential, hospital, day care or other); and supervision model (singleton practice teacher, long-arm practice teacher with a qualified social worker as on-site facilitator, or long-arm practice teacher with an unqualified on-site facilitator). Singleton Practice Teachers are qualified social workers who are qualified field instructors based within the same social work team, agency and setting as the student. Long-arm practice teachers are qualified social workers and field instructors who are employed by the same agency, but in an educative capacity. They rely on on-site facilitators or agency task supervisors to oversee the student's day-to-day case work within the agency. The questionnaire asked students to rate the usefulness of sixteen learning activities for developing their practice competence and professional identity using a four-point Likert scale of 'very useful', 'useful', 'not very useful' or 'not at all useful' (with an option of 'not applicable'). Table 1 sets out these learning activities, which were developed with reference to the key roles for social work and a review of available literature about social work placements. Two open-ended questions generated qualitative data: 'Overall, what did you find most helpful in assisting your learning during PLO?' and 'What would have improved your learning during PLO?’ Information was also collected about the regularity of student engagement with the learning activities during placement and this has been reported elsewhere (Author’s own, 2016).

\section{Recruitment and Sampling}

Each year approximately 260 students graduate in Northern Ireland with the Bachelor of Social Work Degree. The majority are of White British/Irish origin, female and in their mid20s. All full-time undergraduate students registered to study social work at Queen’s 
University Belfast and Ulster University and undertaking placement between January 2013 and May 2014, were invited to participate in the study. Part-time students had already completed placement before ethical approval had been obtained, so were excluded from the study. Students were emailed a participant information sheet at least one week prior to the day when they are recalled to attend teaching at university, which offered an explanation of the research project, and informed them that participation was voluntary and that all questionnaires would be returned anonymously. Following a reminder of the voluntary nature of participation, questionnaires were then distributed to all students during their final recall day lecture at the respective university campus. The return of completed questionnaires at the end of the lectures was regarded as consent to participate. Those not wishing to participate returned blank questionnaires at the same time, which promoted anonymity. During the data collection period, 708 students completed placement but not all attended their University recall day so missed the opportunity to participate. A total of 396 students returned a completed questionnaire, representing a strong response rate of 56\%.

\section{Data analysis}

Statistical analyses were undertaken using SPSS for Windows (Version 20). The rate of missing data was low, ranging from zero to $10 \%$, and missing data were excluded on an analysis-by-analysis basis. The learning activity rating items were coded from 1 (not useful at all) through to 4 (very useful), with a higher score reflecting a better rating. Frequencies and percentages were calculated for all variables and means and standard deviations were calculated for the learning activity rating items. The learning activity rating items were ranked using their mean scores. Independent samples t-tests were used to explore differences in the usefulness ratings of the sixteen learning activities between PLO levels and service user groups. One-way MANOVAs (using SPSS GLM) were used to test for differences in ratings between the three supervision models and the five PLO settings, with Bonferroni post 
hoc comparisons conducted for significant effects. Statistical significance was set at 95\% probability for all tests. For the open-ended questions, 311 students responded to the question: 'Overall, what did you find most helpful in assisting your learning during PLO?' and 246 students responded to 'What would have improved your learning during PLO?’ The responses to these questions were analysed using thematic content analysis (Ritchie \& Lewis, 2003). The principal researcher reviewed the responses, identified the salient information and using a manual method, devised a framework for initial coding of emerging themes. Coauthors read quotations and quotes were selected that encapsulated the semantics of emerging themes or issues not already covered in the questionnaire, and qualitative comments assisted with interpreting quantitative results.

\section{RESULTS}

\section{Respondent characteristics}

Of the 396 respondents, 151 (38\%) reported on first placement and 243 (61\%) on final placement, with an additional two students repeating placement due to previously failing it. Just over half of the students (209, 54\%) were in children's services, with the remainder (177, $46 \%)$ in adult services. Two-thirds of students $(260,67 \%)$ were placed in fieldwork settings, with 64 (16\%) in residential, 26 (7\%) in hospitals, 20 (5\%) in day care and 18 (5\%) in 'other' settings. Three models of supervision were recorded by respondents with the majority having either a singleton practice teacher (181, 46\%) or a long-arm practice teacher with a qualified social worker as on-site facilitator (187, 48\%), with only 24 students (6\%) having a long-arm practice teacher with an unqualified on-site facilitator.

Usefulness of learning activities 
The students' ratings of the usefulness of each of the sixteen learning activities for developing practice competence and social work identity are presented in Tables 1 and 2 respectively.

\section{<Table 1 about here> \\ < Table 2 about here>}

As Tables 1 and 2 show, the learning activity ranked most highly was being given constructive feedback, with around three-quarters of students reporting that this learning activity was very useful for developing both practice competence and professional identity. This is supported by students' responses to the open-ended questions about what they found most helpful in assisting learning, with 46 students mentioning this learning activity. For example, one student reflected on how useful it was when 'receiving feedback and learning from my mistakes during practice learning opportunities i.e. when things went well or not so well with service users’. Another appreciated feedback and supervision for professional growth:

'I believe through the good use of supervision and the constructive feedback which was provided, aided me in identifying areas for improvement which I subsequently was able to achieve.’

Not all feedback was considered helpful though, with students highlighting the negative impact of receiving feedback which was not constructive. One student wanted more 'positive encouragement and constructive criticism about professional practice not personal criticism' and this was echoed by a student who wanted 'more constructive feedback'. 
Supervision was ranked in the top five learning activities for developing both practice competence and social work identity (Tables 1 and 2). In the qualitative comments, 140 students referenced supervision with most valuing 'regular/weekly' supervision in a 'safe' or ‘supportive’ learning environment.

'I was well prepared for PLO and extremely well supported during my PLO by my Practice Teacher and on-site supervisor who both supervised me on a weekly basis.'

Although most found supervision helpful, 41 students recommended improved structure, consistency and objectives; avoiding frequent rescheduling; not over-emphasising case management; and increasing opportunities to link theory to practice. Some experienced difficulties with the supervisory relationship, which was perceived as oppressive and detrimental to the learning process and highlights the power differential between students and practice teachers.

'I felt that more support from my PT [Practice Teacher] would have been a big benefit. I am lucky that my on-site fulfilled some of the PT roles as I feel I would have struggled a lot more. I did not feel comfortable approaching my PT and felt significantly oppressed. I believe that if I had had a more informal, less anxious time with my PT it would have made placement easier.’

As Tables 1 and 2 show, observing the practice teacher or other social work staff was also highly rated and in the qualitative comments, 52 students indicated that shadowing or observing social workers exposed them to 'real world' social work. Whilst most suggested that shadowing opportunities were restricted to the induction, some had continuous opportunities which included: 'attendance at statutory meetings to observe the role and function' or 'observing staff engaging with the young people to learn the different policies, procedures and legislation' and opportunities to hear 'how other team members deal with 
complex issues’. Additionally, sharing office space with fieldwork social workers offered ongoing opportunities to 'listen to work conversations' and to 'listen to staff members on the phone... [or] discuss their cases', which can only be facilitated in some settings, which are prioritised for final year students.

Thinking critically and reflectively about the social work role was particularly important for developing professional identity (Table 2) and there were 72 students who commented on reflecting on practice, which included opportunities to discuss casework in teams or supervision. Some valued times when the team 'sat together every day and spoke about what went well and what didn't go well' and another found 'other social workers in the team were very useful for help and guidance... on how to approach cases' which is unfortunately not available in all placement settings.

A number of students referred to the distraction or stress of completing written academic assignments towards the end of placement, which they believed restricted opportunities for reflection. One student would have preferred:

'Having more time to reflect and read theory around practice issues. I believe I did not have time to do this due to the amount of written work expected in the form of both tuning-ins or evaluations and the academic assignments'.

However, these academic assignments promote opportunities for students to critically reflect on aspects of their social work practice and the international research informing one specific aspect of practice. At the other end of the spectrum, students' ratings also pointed to the learning activities which were least useful for developing practice competence and social work identity (Tables 1 and 2). Less than half of students found 'linking practice to NISCC codes of practice' very useful for developing practice competence (Table 1), with only 60\% of students finding it very useful for developing social work identity (Table 2). In the 
qualitative comments one student suggested 'more emphasis on linking practice to the NISCC codes of practice' which are central to the professional registration of social workers (including students). NISCC codes of practice (more recently replaced with the Standards of Conduct and Practice (NISCC, 2015) form the core regulatory framework for the social work profession in Northern Ireland. Standards of conduct describe the values, attitudes and behaviours expected of workers in the day-to-day role. The standards of practice outline knowledge and skills required for competent practice.

Just under half of the students rated 'learning about socio-demographics and the service user population' as very useful for developing practice competence (Table 1) and only 52\% rated it as very useful for developing social work identity (Table 2). When asked how to improve learning, one student suggested having 'more discussion and direction on socio-demographic issues'. These findings suggest that while some students see links between the wider systems of their service user group and their professional identity, many did not value the usefulness of this activity very highly.

As Tables 1 and 2 show, only just over half of students reported 'linking tasks with practice foci and key roles this activity’ as very useful for developing both practice competence and social work identity. According to qualitative comments, one student recommended more focus on practice and less emphasis on written tuning-in exercises or evaluations of practice, as they were deemed 'repetitive' and 'time-consuming' emphasising their perceived low level of usefulness.

'There was a lot of written work to complete and therefore time-consuming which may have caused extra stress. I had a fantastic learning opportunity but would have preferred to have concentrated all my time on PLO rather than on [academic] work’. 
Despite the need to generate written evidence of competence to meet the practice foci and key roles, which are the cornerstone for assessment of competence by practice teachers during the placement, our results indicate that one in ten students rated this learning activity as either not very useful or not useful at all. The findings seem to suggest that some students found generating written evidence stressful and time-consuming without realising its importance for demonstrating readiness to practice.

\section{Differences in the usefulness of learning activities}

Comparing students' mean ratings of the usefulness of each of the learning activities for developing practice competence and professional identity, there were no significant differences between adult and children’s placements and no pattern of difference between supervision models. However there were differences between students on their final versus first PLO, with students on their final PLO rating five learning activities as more useful for developing practice competence: observe practice teacher/staff (mean of 3.75 versus 3.59 respectively, $\mathrm{t}(360)=2.64, \mathrm{p}=.009)$; have practice observed by practice teacher/staff (3.52 vs 3.38, $\mathrm{t}(370)=2.02, \mathrm{p}=.044)$; learn about role/function of team/organisation (3.74 vs 3.55, $\mathrm{t}(374)=3.44, \mathrm{p}=.001)$; learn about socio-demographic/service user (3.50 vs 3.13, $\mathrm{t}(367)=$ 4.97, $\mathrm{p}<.001$ ); and learn about resources, systems \& networks (3.60 vs 3.41, t(375) = 2.84, p $=.005)$. In addition, as Figure 1 shows, students on their final PLO, compared with students on their first PLO, rated ten learning activities as more useful for developing professional identity: have practice observed by practice teacher/staff $(\mathrm{t}(349)=2.97, \mathrm{p}=.003)$; think critically \& reflectively about SW role $(\mathrm{t}(349)=2.95, \mathrm{p}=.003)$; discuss feelings and values about practice $(\mathrm{t}(351)=2.13, \mathrm{p}=.034)$; learn about role/function of team/organisation $(\mathrm{t}(356)$ $=4.06, \mathrm{p}<.001)$; learn about socio-demographic/service user $(\mathrm{t}(351)=5.29, \mathrm{p}<.001)$; learn about resources, systems \& networks $(\mathrm{t}(348)=3.82, \mathrm{p}<.001)$; learn about legislation, 
policies \& procedures $(\mathrm{t}(349)=2.02, \mathrm{p}=.044)$; link theory and practice $(\mathrm{t}(347)=2.70, \mathrm{p}=$ $.007)$; link practice to NISCC codes of practice $(\mathrm{t}(343)=2.93, \mathrm{p}=.004)$; and link tasks with practice foci and key roles $(\mathrm{t}(348)=2.21, \mathrm{p}=.028)$. These differences might be due, at least in part, to the fact that at the time of data collection final placement students would have completed 200 days of practice learning, whereas first placement students would have only completed 85 days. Additionally, it is only a requirement for all final placement students to have a social work practitioner based on-site, whereas first placement students only require opportunities to shadow or work alongside social work practitioners.

\section{$<$ Figure 1 about here $>$}

Using multivariate analysis, there was no overall difference between placement settings in the rating of the usefulness of the learning activities for developing practice competence (Wilks' $\Lambda=.76, F(64,1165)=1.31, p=.057$, partial $\eta 2=.07)$. However, there was a significant difference between placement settings in the rating of usefulness for developing professional identity (Wilks' $\Lambda=.75, \mathrm{~F}(64,1146)=1.36, \mathrm{p}=.036$, partial $\eta 2=.07)$. As Table 3 shows, there were significant differences between placement settings for five learning activities: observing the practice teacher or other staff; being given constructive feedback about progress; discussing and reflecting on practice skills; linking theory and practice; and learning about resources, systems and networks. Post hoc analyses suggest that these differences were, at least in part, due to the relatively low ratings of students in day centre settings. Students placed in day centres, compared with those in hospital settings, had lower usefulness ratings for discussing and reflecting on practice (mean difference $=-.58$, SE $=.18$, $\mathrm{p}=.018$ ) and linking theory and practice (mean difference $=-.67, \mathrm{SE}=.18, \mathrm{p}=.004$ ).

Students in day centres also had lower ratings for discussing and reflecting on practice than 
those in fieldwork placements (mean difference $=-.46, \mathrm{SE}=.15, \mathrm{p}=.024$ ). In addition, students in hospital settings had higher ratings for the usefulness of observing practice teacher and other staff than those in 'other' settings (mean difference -.55 , SE $=.19, \mathrm{p}=$ .036). There were no other statistically significant differences on post hoc analysis.

While caution needs to be exercised when interpreting these results due to the low number of students placed in day centre settings, qualitative comments provide further support and suggest a number of students in day centre and supported living placements felt disadvantaged by the absence of a clearly defined social work role and the absence of a social worker on-site, who they could have observed or worked alongside. One student on placement in an adult day centre indicated it was a 'great placement for developing, particularly, communication skills. However, there was no social work role as such, so I feel that my learning has been minimal'. Some other students in day care or supported living accessed supplementary learning opportunities:

'If I had got more field work experience in the community, as was promised before I started practice as there was no social work role in my PLO. I had to create my own work, which was annoying at times’.

Another student who had a split placement between residential care for older people and supported living with older people shared the following:

‘At the start I didn’t like the environment, but in the end I loved it. I didn't get a lot from it as I was more like a support worker than a social worker. I think I saw one social worker the whole time so I felt, what is my role...I didn't know what it was'. These findings suggest that students in settings where there was no social work role model, felt disadvantaged and unclear about the role of a social worker, which may have resulted in issues around readiness to practice and identity when progressing into final year.

\section{<Table 3 about here $>$}




\section{Study limitations}

Students enrolled in the two social work programs in Northern Ireland are generally a homogenous group in terms of gender and age but it would have been interesting to collect some demographic data to explore the composition of the sample and to possibly explore any differences between these groups. The timing of data collection was constrained by regionally agreed days when students are recalled to university for teaching. Although most questionnaires were administered on the final day of placement, some were distributed in the final few weeks of placement and new experiences may have altered responses. Not all students provided qualitative responses in response to the questions about what they found most helpful in assisting learning during PLO and what would have improved their learning during PLO. Only students who successfully completed placement attended final recall days, meaning students who failed or withdrew from their placement did not complete a questionnaire. However, they only accounted for approximately 3\% of the potential pool of students.

\section{DISCUSSION}

This study provided an opportunity to explore which practice learning activities qualifying social work students valued most for promoting practice competence and professional identity. Findings revealed the centrality of the supervisory relationship, the importance of observing social work practice, critical reflection on practice and constructive feedback. Findings also revealed that knowledge related learning activities, which are integral to the NISCC professional standards of practice (NISCC, 2015) and professional registration of social workers with the Health and Social Care Regulator (NISCC) need to be prioritised and valued more by social work students. 


\section{Centrality of the supervisory relationship}

Supervision is highly valued by students (Bogo, 2015) and is central to student learning during placement as it offers space for direction, support, reflection and guidance (Field, Jasper \& Littler, 2016). The Northern Ireland Social Work Degree Partnership’s Regional Practice Learning Handbook (2015) recommends a minimum frequency (fortnightly) and duration of supervision (two hours) for qualifying students. In our study, supervision was highly rated by students for developing both practice competence and social work identity. Qualitative findings confirmed that students positively valued 'regular' formal supervision and emphasised the importance of a 'supportive' supervisory environment. As outlined previously (Author's own, 2016) most of our students had a positive supervisory relationship with an experienced or dedicated practice teacher, where they received constructive feedback, critically reflected on practice and discussed feelings or values. These were highly valued learning activities in terms of usefulness for developing practice competence and professional identity and echo the critical factors that Bogo (2015) recommends to promote student learning (i.e. creating a positive learning environment, collaborative relationships, debriefing after observation, reviewing practice and providing feedback). However, a number of students in our study recommended that supervision sessions could be better structured with clearer objectives, (some students recommended improving the structure, consistency and objectives of supervision, avoiding frequent rescheduling; not over-emphasising case management; and increasing opportunities to link theory to practice.

\section{Importance of observing and critically reflecting on practice}


Learning activities highly valued were observing/shadowing other social workers, receiving constructive feedback and thinking critically and reflectively about social work practice. Bogo (2015) commended teams who welcome students and view observing and knowledge exchange as mutually beneficial. Our students valued opportunities to shadow social workers with those in hospitals finding it most useful. Some indicated that shadowing opportunities were concentrated at induction and recommended extending these throughout placement. Lee \& Fortune (2013) reported that students who had higher social work skills towards the end of placement had reported opportunities for observing professionals over all time points, as it offered clear direction on how to develop their professional skills. Students in settings with no social work presence missed important opportunities to listen and watch the role of social work, so reported that observing was not useful and suggested that additional opportunities to observe social workers would have helped to define their understanding of the professional social work role. Furness \& Gilligan (2004) raised concerns about students not having a social work role model. Bogo (2015, p. 309) recommends that opportunities to 'observe and debrief with experienced practitioners' should include the practice teacher and team members as they can serve as exemplary role models to students. In Northern Ireland, regularly working alongside social work staff is currently only stipulated for final year students (DHSSPSNI, 2010) meaning that placements with no social work role model are used for first placements and limit their exposure to social work practice.

Sharing office space with qualified social workers and shadowing practice were highly valued by our students as it demystified the social work role and provided opportunities to observe specific skills. Students who were not afforded this opportunity felt disadvantaged and unclear about their role. Whilst Bogo (2015) supports shadowing or observing, she acknowledged that it needs to be supplemented with critical reflection on practice and students need to make links between theory and practice. Furthermore, Houston (2015, p. 8) 
argues that without critical reflection in supervision and reflexivity on practice social workers are at risk of: adopting ‘biased or distorted thinking', breeding oppressive structures and failing to safeguard service users. It has been suggested that at the beginning of placement, students need clear direction and will only improve their critical thinking as they progress through their training, mature and become responsible learners (Grow, 1991).

The most highly rated learning activity for developing both practice competence and professional identity was being 'given constructive feedback' which was previously pinpointed as an essential learning strategy to promote social work identity and competence (Fortune, McCarthy \& Abramson, 2001). Given how self-report and self-assessment of practice is often distorted (Bogo, Rawlings, Katz \& Logie, 2014) practice teachers must observe practice and provide constructive feedback which students value more if they have a trusting and supportive supervisory relationship (Bogo, Regehr, Power \& Regehr, 2007; Eva, Armson, Holmboe, Lockyer, Loney, Mann \& Sargeant, 2012; Miehls, Everett, Segal \& Du Bois, 2013). Our findings indicated that students were open to positive and negative feedback to promote professional growth, as it enabled them to reflect on interventions with service users or carers. A minority of students found feedback detrimental with some feeling comments were personalised rather than constructive. According to Bogo (2015, p. 320) providing 'multiple opportunities to actually practice' helps make and 'strengthen new neuronal connections' enabling students to make sense of new knowledge, which needs to be supplemented with constructive feedback on practice and links made between theory and practice. According to the 'Statements of differential for levels 'in the Practice Learning Handbook (NIDSWP, 2015) first placement students are only expected to demonstrate a beginning ability to analyse, evaluate, recognise and understand practice issues, whereas final placement students are expected to demonstrate an informed and critical awareness of agency function, a confident and competent use of self, and critically apply theory to practice, which 
mirrors findings from research regarding the progression students make regarding 'observational-participatory activities’ and ‘conceptual linkage activities’ (Lee \& Fortune, 2013, p. 421). This may offer some explanation into the differences between our two groups of students regarding their perceptions about which learning activities were most useful in developing readiness for practice and feelings of competency whilst developing their sense of professional social work identity.

\section{Revaluing knowledge for practice learning activities}

Knowledge for practice activities (linking practice to NISCC codes of practice, practice foci, key roles and theory) were not valued highly. Only half of our respondents regularly undertook these learning activities during placement (Author, 2016) which may explain why fewer students had such low ratings of the usefulness of these activities in terms of developing practice competence and developing social work identity. The qualitative comments further suggested that many students felt stressed and overwhelmed when ‘juggling’ academic assignments or written tasks to evidence competence, which had to be completed towards the end of the placement and impacted on their ability to focus on the casework. This confirms that the students did not value these 'knowledge for practice' activities, which is worrying, given the fundamental importance of the NISCC Codes of Practice (now NISCC Standards for Conduct and Practice, 2015) which stipulate adherence to 'statutory and professional codes, practice, frameworks and guidance' and underpin social work values, policy and practice (DHSSPSNI \& NISCC, 2015, p. 8). Likewise, generating written evidence which provided opportunities for linking theory to practice was not highly valued despite social work being promoted as an academic discipline underpinned by theories of social work and social sciences with the need for theory to heighten our understanding of the 'psychological, social, cultural and economic spheres' needed to promote reflexivity 
(Houston, 2015, p. 8). According to Fortune, McCarthy \& Abramson (2001) these ‘conceptual linkage activities’ provide a very important context to social work principles underpinning practice, and offer opportunities for practice teachers to assess competence. Higher education has been accused of failing to produce graduates fit for practice (Williams, 2009; Donnellan \& Jack, 2009). Inquiries and reviews highlight shortfalls and make recommendations for social work training which promote professional identity and competence (Houston \& McColgan, 2014). Given that all respondents had successfully completed placement, the subsequent value attributed to these activities raises questions about how practice teachers assess students' competence of 'knowledge for practice' activities and whether there could be greater emphasis on assessment through supervision and observing practice, rather than so many written tasks. To ensure appropriate gate-keeping of entry into the profession (Sowbell, 2012), there is a need for strict regulation of practice placements and quality assurance of student placements to ensure that students are undertaking a variety of learning tasks, managing a caseload and being regularly observed and supervised in practice.

Differences noted between first and final placement students regarding perceived usefulness of these learning activities on professional identity could be explained by the fact that students nearing qualification were expected to be more confident with their professional identity when compared to less experienced students. Final year students from the two programs in Northern Ireland believed they could have received improved preparatory teaching through the inclusion of 'real life' examples in the Preparation for Practice Learning Skills module or completing a ‘community profile’ prior to commencing placement. Others suggested better insight into the types of evidence that could be generated to meet the practice foci, more emphasis on social work practice rather than NISCC or practice foci, and 
others expected more guidance on the academic assignments in recall day lectures and tutorials, which would enable teaching to align with students’ demanding social work roles and everyday practice (Houston \& McColgan, 2014).

\section{Summary}

This paper supports the centrality of supervision and proposes an ideal supervisory relationship, where the practice teacher takes lead responsibility for facilitating regular meetings, generating a safe and supportive learning environment and regularly providing constructive feedback on practice and progress. Practice teachers have the responsibility to evaluate student performance in the field and to determine if students are prepared for practice (Bogo, Regehr, Power, \& Regehr, 2007). Equally important is the responsibility of University educators to promote and find creative ways to incorporate ethics and practice into the curriculum so that students understand their contribution for enhancing a sound knowledge and value base for practice. Despite this charge, there exists relatively little empirical literature informing what learning tasks promote their competence and suitability for practice. This research suggests that students' perceptions of their readiness for practice relies heavily on a strong social work presence that they can observe and model social work practice throughout their placement. All students should be encouraged to critically reflect on practice and underpin their practice with theory. Encouraging students to link practice to key

roles, national occupational standards and professional standards of conduct and practice is a shared responsibility and may enable students to feel more confident with practice competence and social work identity.

\section{References}

Author (2012).

Author (2015).

Author (2016). 
Bates, N., Immins, T., Parker, J., Keen, S., Rutter, L., Brown, K., \& Zsigo, S. (2010).

Baptism of fire: The first year in the life of a newly qualified social worker. Social Work Education, 29(2), 152-170.

Bellinger, A. (2010). Studying the landscape: Practice learning for social work reconsidered. Social Work Education, 29(6), 599-615.

Bogo, M. (2006). Field instruction in social work: A review of the research literature. The Clinical Supervisor, 24(1-2), 163-193.

Bogo, M. (2010). Achieving competence in social work through field education. Toronto, ON: University of Toronto Press.

Bogo, M. (2015). Field education for clinical social work practice: best practices and contemporary challenges. Clinical Social Work Journal, 43, 317-324.

Bogo, M., Regehr, C., Woodford, M., Hughes, J., Power, R., \& Regehr, G. (2006). Beyond competencies: Field instructors' descriptions of student performance. Journal of Social Work Education, 42(3), 191-205.

Bogo, M., Regehr, C., Power, R., \& Regehr, G. (2007). When values collide: Field instructors' experiences of providing feedback and evaluating competence. The Clinical Supervisor, 26(1/2), 99-117.

Bogo, M., Rawlings, M., Katz, E., and Logie, C. (2014). Using simulation in assessment and teaching: OSCE adapted for social work. Alexandria, VI: Council on Social Work Education. Boud, D. (1995) Enhanced learning through self assessment. London, UK: Kogan Page.

College of Social Work (2012). Quality Assurance in Practice Learning, $2^{\text {nd }}$ edition. Leeds: Skills for Care.

Croisedale-Appleby, D. (2014). Re-visioning social work education, An Independent Review, dated February 2014, David Croisdale-Appleby. 
Csiernik, R. (2001) The practice of field work: What social work students actually do in the field. Canadian Social Work, 3(2), 9-20.

Department of Health (2002). Requirements for Social Work Training, Department of Health, London.

Department of Health, Social Services and Public Safety Northern Ireland (2010). Regional Strategy for Practice Learning 2010-2015. Northern Ireland: DHSSPS.

Department of Health, Social Services and Public Safety and Northern Ireland Social Care Council (2014). Northern Ireland Framework Specification for the Degree in Social Work. Northern Ireland: DHSSPS.

Donnellan, H., \& Jack, G. (2009). The Survival Guide for Newly Qualified Child and Family Social Workers: Hitting the Ground Running. London: Jessica Kingsley Publishers. Eva, K. W., Armson, H., Holmboe, E., Lockyer, J., Loney, E., Mann, K., \& Sargeant, J. (2012). Factors influencing responsiveness to feedback: On the interplay between fear, confidence, and reasoning processes. Advances in Health Science Education, 17(1), 15-26. Field, P., Jasper, C., \& Littler, L. (2016) Practice Education in Social Work: Achieving professional standards ( $2^{\text {nd }}$ ed). Northwich: Critical Publishing Limited. Fortune, A.E., Feathers, C.E., Rook, S.R., Smollen, P., Stemerman, B., \& Tucker, E.L. (1985) Student satisfaction with field placement. Journal of Social Work Education, 21(3), 92-104. Fortune, A., \& Kaye, L. (2002) Learning opportunities in field practica: Identifying skills and activities associated with MSW students' self-evaluation of skill performance and satisfaction. Clinical Supervisor, 21(1), 5-28.

Fortune, A., McCarthy, M., \& Abramson, J. (2001). Student learning processes in field education: Relationship of learning activities to quality of field instruction, satisfaction, and performance among MSW students. Journal of Social Work Education, 37(1), 111-124. 
Furness, S., \& Gilligan, P. (2004). Fit for purpose: issues from practice placements, practice teaching and the assessment of students' practice. Social Work Education. The International Journal, 23(4), 465-479.

Fortune, A. E., \& Lee, M. (2004) Student's access to educational learning activities and learning outcomes in field education. Paper presented at the Eighth Annual Conference of the Society for Social Work and Research, New Orleans, LA.

Grow, G. (1991) Teaching learners to be self-directed. Adult Education Quarterly, 41(3), 125-149.

Houston, S. (2015). Reflective Practice: A model for supervision and practice in social work. Belfast: Northern Ireland Social Care Council.

Houston, S., \& McColgan, M. (2014). Delivering social work education on case reviews and inquiry reports: An exploratory study of students' perspectives in Northern Ireland. Child Care in Practice, 20(4), 415-435.

International Federation of Social Workers (IFSW) (2014). Global Definition of Social Work. IFSW General Meeting and the IASSW General Assembly in July 2014.

http://ifsw.org/policies/definition-of-social-work/

Lee, M. \& Fortune, A.E. (2013) Patterns of field learning activities and their relation to learning outcome. Journal of Social Work Education, 49(3), 2163-5811.

Lefevre, M. (2005). Facilitating practice learning and assessment: The influence of relationship. Social Work Education, 24(5), 565-83.

Miehls, D., Everett, J., Segal, C., \& Du Bois, C. (2013). MSW students’ views of supervision: Factors contributing to satisfactory field experiences. The Clinical Supervisor, 32(1), 128-146.

McKee, E. Muskat, T., \& Perlman, I. (2015) Students Today, Educators Tomorrow: Shaping the Social Work Curriculum to Enhance Field Education, Field Educator, 5(2). 1-6. 
Nixon, S. \& Murr, A. (2006). Practice learning and the development of professional practice. Social Work Education, 25(8), 798-811.

Northern Ireland Social Care Council (2011). National Occupational Standards for Social Work. Belfast: NISCC.

Northern Ireland Degree in Social Work Partnership (2015). Regional Practice Learning Handbook 2015-16. Belfast: NISCC. Available at: http://www.niscc.info/degree-in-socialwork/practice-learning-for-social-work

Northern Ireland Social Care Council (2015). Standards for Conduct and Practice for Social Work. Belfast: NISCC. Available at:

http://www.niscc.info/storage/resources/web_optimised_91740_niscc_standards_of_conduct _and_practice_bluepurple.pdf

Power, R., \& Bogo, M. (2002). Educating field instructors and students to deal with challenges in their teaching relationships. Clinical Supervisor, 21(1), 39-58.

Regehr, C. (2013). Trends in higher education in Canada and implications for social work education. Social Work Education: The International Journal, 32(6), 700-14.

Ritchie, J., \& Lewis, J. (2003). Qualitative Research Practice: A Guide for Social Science Students and Researchers. London: Sage Publications.

Shardlow, S., \& Doel, M. (1996) Practice learning and teaching. London, UK: Macmillan. Skehill, C. (2005). Child protection and welfare social work in the Republic of Ireland: Continuities and discontinuities between the past and the present in Kearney, N., \& Skehill, C. (eds). Social Work in Ireland: Historical Perspectives. Dublin, Institute of Public Administration, 127-46.

Social Work Task Force (2009). Building a Safe, Confident Future: The final report of the Social Work Task Force. Available at: https://www.education.gov.uk/publications 
Sowbell, L. R. (2012). Gatekeeping: Why shouldn’t we be ambivalent? Journal of Social Work Education, 48(1), 27-44.

Williams, C. (2009). Social work degree failing to prepare students. Community Care, February $6^{\text {th }}$.

Wilson, G., Walsh, T., \& Kirby, M. (2008). Developing practice learning: Student perspectives. Social Work Education, 27(1), 35-50. 